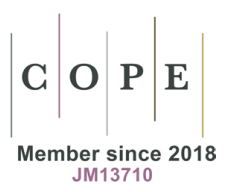

EUROPEAN SPATIAL RESEARCH AND POLICY

Volume 27 2020

Number 1

http://dx.doi.org/10.18778/1231-1952.27.1.01

\author{
Grzegorz MICEK* (D)
}

\title{
STUDIES OF PROXIMITY IN COWORKING SPACES: THE BASIC CONCEPTUAL CHALLENGES
}

\begin{abstract}
The article aims to identify main research challenges in studying coworking spaces (CSs) within the field of economic geography. It combines the perspective of proximity economics with the growing body of papers about spatial aspects of the operations of CSs and their role in stimulating collaboration. Based on a review of literature, the author identified the characteristic features of CSs and the corresponding proximity dimensions. He further assessed the significance of various dimensions of proximity in CSs. The article reveals how various proximities differ between CSs. It also distinguished the research strands referring to the spatialities of CSs. Next, it discusses the conceptualisation and operationalisation of proximity. Then, it applied it in the micro-scalar context of coworking spaces. The paper sheds a new light on 'real CSs' as physical spaces of strong institutional, cognitive and social proximities. It has been argued that even if organisational proximity in CSs is taken for granted, there is a heterogeneity amongst their users.
\end{abstract}

Key words: coworking spaces (CSs), collaborative spaces, new working ecosystems (environments), proximity, operationalisation.

\section{INTRODUCTION}

Modern economy has transformed working ecosystems. High-tech industries and advanced business services are offered both from permanent firm locations and temporary settings. The first type is represented by various innovation districts (Katz and Wagner, 2014; Katz et al., 2015), business or technology parks and incubators, whereas the latter is by multiple venues of a temporary nature such as fairs, conventions, business meetings, etc. Work is also performed at multiple places such as customers' locations, co-working spaces (Parrino, 2015; Kojo and Nenonen, 2017), open creative labs (Schmidt and Brinks, 2017; Brinks, 2019),

\footnotetext{
* Grzegorz MICEK, Jagiellonian University, Institute of Geography and Spatial Management, Gronostajowa 7, 30-387 Kraków, Poland; e-mail: grzegorz.micek@uj.edu.pl, ORCID: https://orcid. org/0000-0001-9552-9326
} 
makerspaces (van Holm, 2017) and fabrication laboratories 'Fablabs' (Schmidt et al., 2014; Pauceanu and Dempere, 2018; Suire, 2019). The paper focuses on coworking spaces (CSs) as a subtype of collaborative spaces. Their dynamic emergence and growth is evident: between 2015 and 2019 the number of CSs rose 2.5 times and the number of users almost quadrupled exceeding 2.1 million by the end of 2019 (2019 Coworking Forecast, 2019).

Various social and organisational factors impact the growth of collaborative places. These include (Schmidt et al., 2016; Schmidt and Brinks, 2017) increasing project orientation of work which influences the forms of organising work and labour, the growing number of firms following the 'open innovation' model, more community-led urban regeneration, and unusual players involved in entrepreneurial agency.

Both in permanent and temporary settings, work may be performed in close spatial proximity. Studies of the interplay between physical proximity and knowledge interactions provide mixed evidence on its range and importance. On the one hand, there is a growing concern that "co-working places" appear to be more about people and connectivity than the physical spaces themselves" (Kojo and Nenonen, 2017, p. 171). Not only the physical milieu, but also co-location alone should not be claimed to stimulate networking and collaboration (Fuzi, 2015). Following this approach, it is social or organisational proximity that facilitate knowledge interaction. In CSs in Milan (Parrino, 2015) the simple co-location did not facilitate accidental knowledge exchanges. From this perspective, "geographical proximity seems rather to have a key role in favouring the exploration of similarities and contact points among co-workers only under certain conditions". (Parrino, 2015, p. 270), However, for proximity economics small geographical distance is claimed to be complementary to relational (social, organisational, institutional and cognitive) proximities (Boschma, 2005). In the context of 'innovation districts' Katz et al. (2015) emphasised the increasing value of 'place' in stimulating knowledge interactions and collaboration. The belief is that physical assets affect the vibrancy of communities and knowledge interactions. Mariotti et al. (2017, p. 48) argued that another diffused hypothesis "is that relational and geographic proximity within these new working spaces may foster information exchange and business opportunities" (Spinuzzi, 2012) through face to face contacts. To sum up, it must be argued that the geographical research on knowledge interactions does neglect the link between social context and physical place (Rutten, 2017). The research that deals with interrelations between organizing work in new working environments, various established proximities (distances) and the materiality of such spaces remains scarce. Both temporary and permanent settings should be regarded as spatial manifestations

\footnotetext{
${ }^{1}$ One must bear in mind that there is a difference between coworking and co-working. While the term 'coworking spaces' refer to shared workspaces, the latter term ('co-working') stands for collaborative activities between individuals who are a part of the same organisation (Associated Press Stylebook, 2019).
} 
of the relation between knowledge interactions and physical space. Hence, the issue of involved spatial scales has emerged. Even if knowledge creation takes place within global knowledge communities, it is shared in a particular open creative lab (Schmidt and Brinks, 2017). Hence, all CSs may be regarded as local anchors for global knowledge communities and places which may link and enhance a local buzz through global pipelines (Bathelt et al., 2004).

CSs may be positioned as 'third places' (Oldenburg and Brisset, 1982; Oldenburg, 1989) as Moriset (2014) suggested as emerging hybrids of 'telecentres', 'business centres' and 'start-up incubators' (Waters-Lynch et al., 2016). These new working ecosystems are 'neither office nor home' (Ross and Ressia, 2015) that combine formal and informal interactions in one new work environment between individuals (Brown, 2017). In contrast to traditional third places such as coffee shops, beauty parlours, bookshops or bars, CSs provide the basic office infrastructure (Akhavan et al., 2019). Hence, CSs differ from the other third places and they are treated as a hybrid form of the other three places and classify them besides comingling and co-living spaces, as 'fourth places' (Morrison, 2018) - the most important venues for knowledge sharing, social interactions and network creation. At least in theory, these new work environments are not dominated by the logic of hierarchies or markets, but by the logic of social relations (Waters-Lynch et al., 2016).

In this review article, I aim to identify the research challenges for proximity-related studies of coworking spaces (CSs). I argue this includes two crucial issues of the conceptualisation and operationalisation of proximity in the micro-scalar context of CSs. The structure of the article is as follows: the next section provides a review of the literature on coworking spaces with a novel identification of research strands referring to the spatialities of CSs. Then, based on an overview of the literature, the conceptualisation and operationalisation of the dimensions of proximity are discussed. In Section 2, the main research gaps and challenges are presented, including the definition of CSs. Subsection 2.2. suggests methods for the measurement of the various dimensions of proximity in CSs. Finally, selected conceptual links between CSs and various theories and constructs are discussed in Subsection 2.3.

\subsection{Recent studies of the relations between CSs and space}

Several literature review papers on the co-working phenomenon have been published recently (Waters-Lynch et al., 2016; Brown, 2017; Bouncken and Reuschl, 2018; Yang et al., 2019; Orel and Dvouletỳ, 2020). Waters-Lynch et al. (2016) examined co-working as a complex social and spatial phenomenon. However, they have only posed (but have not answered) some questions on the relations between: the spatial distribution of CSs and economic activities in general; and between 
CSs, residential location and urban mobility. Brown (2017) has questioned the popular view (Moriset, 2014; Gandini, 2015) that CSs may secure urban transformation, especially in smaller cities. In contrast, she has recognised the vital role of CSs' managers who curate CSs, namely select workers, particular co-working values (culture), and engagement strategies, and consequently build relations and provide knowledge (Brown, 2017).

Originally, co-working as a communitarian means of addressing work is more about sharing similar values and disseminating knowledge than about physical space (Brown, 2017). However, even if the infrastructure of CSs is often used by remote workers, the analysed phenomenon takes places in a bounded area with a specific design, layout and ambience (Ross and Ressia, 2015; Orel and Alonso Almeida, 2019). There are also local surroundings that may be affected by the operations of CSs. Hence, this article tends to position the operations of CSs in economic geography and regional studies. It focuses on relations between CSs and local or regional space.

I have conducted a systematic literature review of the Web of Science Core Collection database. First, I addressed the query with the use of following phrases 'coworking spaces', 'co-working spaces' and 'collaborative spaces'. It resulted in 1,781 papers. Second, I narrowed down this query to six following academic disciplines and subdisciplines (Web of Science categories): geography, management, social sciences interdisciplinary, urban studies, regional and urban planning, sociology and business. It resulted in 460 papers. Third, I read the abstracts of these papers in order to eliminate papers that did not focus on the relations between CSs and space. Finally, I selected 81 papers with this specific focus. As a result, four strands of literature that explicitly referred to the spatial aspects of functioning of CSs have been identified.

First, there is a couple of conceptual contributions referring to the interplay between time, place and social practices in knowledge work (Rutten, 2017), involving the studies of various proximities (Parrino, 2015) or related variety/local diversification (Suire, 2019). This group of research consists of conceptual considerations focusing on the social and economic transformations that drive the rise and diffusion of CSs. It corresponds with the analysis of CSs at the macro level (Ivaldi, 2017) which examines the broader social and economic context of the functioning of such spaces.

Second, there are classical papers on CSs' location factors (Mariotti et al., 2017). This strand of literature represents the meso level of the analysis of CSs, which considers the coworking organisation or CS as the unit of analysis (Ivaldi, 2017). Capdevila (2017, p. 87) argued that in the case of CSs, "the specific location plays a more important role than in the case of hackerspaces or FabLabs." It is generally agreed upon that there are multiple CS location factors. Based on the research conducted in Milan (Mariotti et al., 2017), the most crucial location determinants include: urbanisation and localisation economies, market size and potential, skilled labour force availability and business opportunities, and transportation accessibility. 
Urbanisation economies are manifested in 'creative clusters' that attract CSs. Additional factors include "low real estate prices, former industrial buildings' availability, and 'personal' considerations" (Mariotti et al., 2017, p. 61).

Third, the most common topic of the studies of CSs is to what extent and how CSs enhance knowledge interactions (van Winden et al., 2012; Mariotti et al., 2017), relationships (Kojo and Nenonen, 2016), social support (Bianchi et al., 2018) the collaboration between individuals (Spinuzzi, 2012; Bilandzic et al., 2013; Ross and Ressia, 2015; Bianchi et al., 2018), creativity (Katz et al., 2015) and, consequently, innovation (Capdevila, 2015; Brinks, 2019). Based on the empirical study conducted in Open Creative Labs in Barcelona, Brinks (2019) discovered that these new working ecosystems have been substantial resources for innovation. By some scholars (Moriset, 2014) collaboration and innovation generation seem to be semi-automatic and CSs are regarded as 'serendipity accelerators' where social encounters are obvious.

However, the direct impact of coworking spaces on collaboration and innovation is often questioned (Ross and Ressia, 2015; Brown, 2017). For instance, Cabral and van Winden (2016) have suggested it is often taken for granted that CSs contribute to innovation (Botsman and Rogers, 2011). In this respect, the strongest critique has been raised by Brown (2017), who thoroughly questioned the role of physical co-location and has argued that spontaneous knowledge sharing does not "just happen" in close proximity and, consequently, the "serendipity machine" (Olma, 2012; Brown, 2017) seems to be a myth.

The multi-scalar character of innovation processes was often neglected by economic geographers (Bunnell and Coe, 2001; Brinks, 2019), who ignored the micro-scale of analysis in the localised innovation processes (Capdevila, 2015). However, various spatial scales are believed to be affected by CSs' operations (Capdevila, 2015). Besides the individual and company levels, at the rarely-studied in economic geography micro-local (community) level, CSs generate a 'micro-local buzz' and represent specialised innovation communities that are often able to coordinate heterogeneous knowledge bases (Capdevila, 2015). They are believed to form micro-clusters which, by operations of individuals, provide crucial dynamics of innovation, but at another spatial and organisational (non-firm) scale than typical clusters. At the local (district or city) level, CSs may integrate locals and co-workers in collective innovation processes (Capdevila, 2015). CSs contribute to urban creativity and sustaining innovation (Moriset, 2014; Weijs-Perrée et al., 2019). Global pipelines (Bathelt et al., 2004) are established by foreign professionals providing external knowledge, while visiting CSs (Capdevila, 2015).

Fourth, at the meso level of analysis (Ivaldi, 2017), the local economic and infrastructural impact of CSs is studied (Mariotti et al., 2017). The following effects have been distinguished in the literature:

- micro-scale physical transformations (Mariotti et al., 2017; Akhavan et al., 2019). CSs' contribution to the improvement of the surrounding public space is recognised 
(Akhavan et al., 2019), although it has been questioned by Brown (2017) whether CSs may be a "quick fix" urban renewal solutions (Moriset, 2014; Gandini, 2015);

- the collaboration between coworking spaces and local community initiatives, which results in, e.g. the creation of social streets (Akhavan et al., 2019). This distinct and rather rare tool in a given city or state is a way of dealing with social exclusion and creating vibrant communities that join co-workers and the locals (Akhavan et al., 2019). In that way CSs may contribute to urban regeneration in the social sense (Akhavan et al., 2019). It has been argued that the effects produced by CSs in their urban context are clearer at the urban scale than at the local scale (Mariotti et al., 2017);

- new job creation (van Holm, 2017; Wolf-Powers et al., 2017); induced and indirect multiplier effects (Micek, 2011) which are hardly recognised;

- the triggering of entrepreneurship (Fuzi, 2015; van Holm, 2017; Wolf-Powers et al., 2017). CSs provide various forms of support (for a discussion on social support, see Gerdenitsch et al., 2015) and facilities for start-ups. In regions that are lagging, CSs provide hard infrastructure designed in such a way that the social, emotional and financial support necessary for entrepreneurship can also emerge (Fuzi, 2015). On one hand, in large cities CSs may provide new business opportunities (Cabral and van Winden, 2016). On the other hand, Brown (2017) has revealed that CSs in smaller cities struggle to find new members necessary to ensure financial sustainability. The main target of CSs' operations may sometimes be reduced to providing subsidised office space (Rus and Orel, 2015).

The local economic, social and infrastructural impact depends on ownership structure, the types of users and businesses, and the local and regional contexts (especially the types of local milieu). That is not always positive. In the case of top-down CSs, Brown (2017, p. 121) questioned whether "the benefits of coworking reached beyond immediate members or that linkages were established between coworkers and local (resident or business) communities." Additionally she rightly indicated the "local/non local" tensions if CSs attract businesses and people from outside a neighbourhood (Brown, 2017).

\subsection{The dimensions of proximity}

One of the constructs most often discussed in modern economic geography is the concept of proximity. This concept combines two basic theoretical approaches: agglomeration and network economies. However, inter-organisational proximity is a subject of research for many disciplines, including economics, sociology, and management sciences. Most often, it is assumed that proximity means belonging to the same group or the degree of similarity (convergence) between objects autonomous from each other in different dimensions. Therefore, inter-organisational proximity should be treated as a multidimensional variable (Rodriguez-Pose, 
2011; Mattes, 2012) and, according to Godart (2012), an exhaustive typology of its dimensions has not yet been developed. Currently, the division provided by Boschma (2005) is the most popular in economic geography. He highlighted geographical, social, cognitive, organisational and institutional proximity (Fig. 1)2. Although the dimensions of proximity suggested by Boschma (2005) slightly overlap Moodysson and Jonsson's ones (2007), the division is already widely used in the literature and has been used in this article.

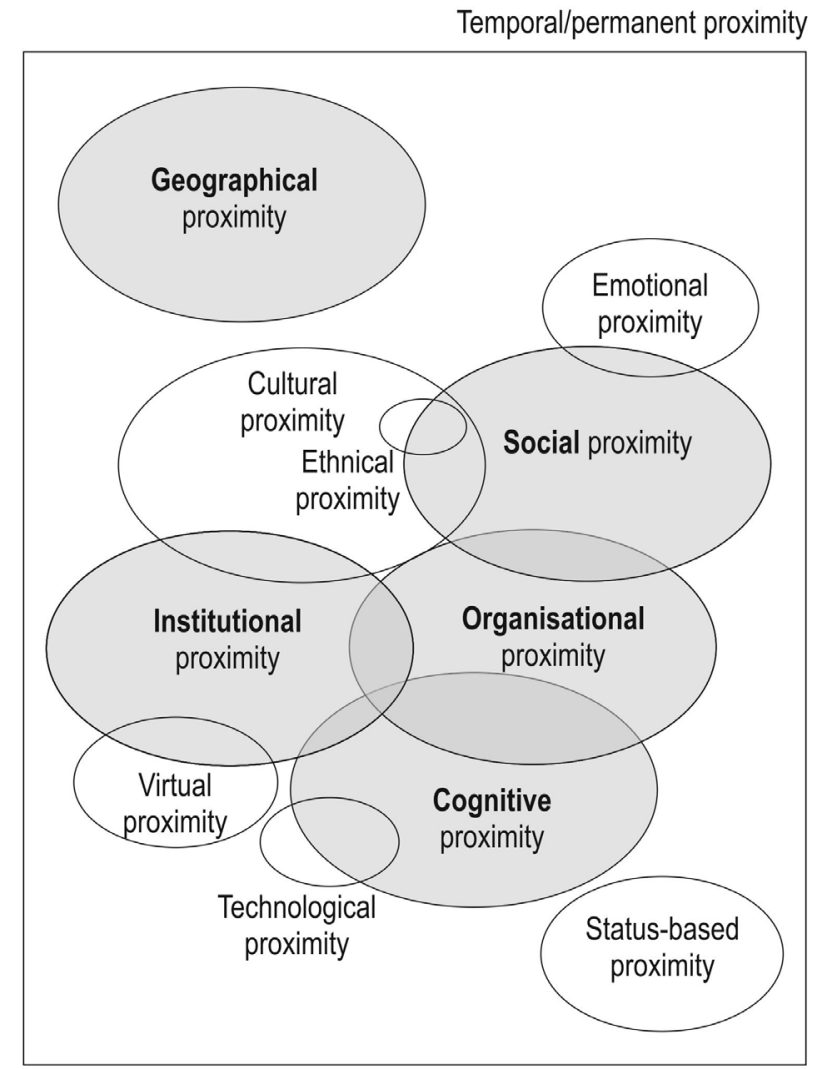

Note: In bold, dimensions distinguished by Boschma (2005)

Fig. 1. Relations between various dimensions of proximity

Source: derived from Micek (2017), modified.

\footnotetext{
${ }^{2}$ Previous research also distinguished other types of proximity: cultural (Gill and Butler, 2003; this can be treated as an element of institutional proximity, see Knoben and Oerlemans, 2006) and technological proximity (Basile et al., 2012; often equated with cognitive proximity), as well as proximity based on the status within the hierarchy (status-based proximity; Godart, 2015; expressed by the age of the actor and their position in the sector and the degree of similarity in terms of stylistic identification and selection of seasonal trends).
} 
In comparison to the previous divisions, Boschma (2005) proposed the introduction of the cognitive dimension of proximity. Currently, it is most often recognised that cognitive proximity is based on the similarity between the so-called knowledge bases available to both actors (Broekel and Boschma, 2012). Depending on the subject of research, there are two approaches to the operationalisation of cognitive proximity. The first analyses the compliance of patent technology classes, determined on the basis of relevant classifications (Fritsch and Slavtchev, 2011; Balland, 2012; Broekel and Boschma, 2012). The second approach verifies whether an enterprise is classified within the partner's sector or industry. An advanced approach in this case is the analysis of the degree of similarity between NACE classification codes. Broekel and Boschma (2012) and Broekel et al. (2015) have recognised that two enterprises are cognitively close when they share the first three digits of the NACE code. Unfortunately, the operationalisation of the concept of cognitive proximity can be much simpler. In the studies of the global navigation satellite sector, Balland (2012) distinguished four subsectors: infrastructure, hardware, software, and services. When two entities belong to one of these they are in cognitive proximity. A very reasonable division of cognitive proximity based on knowledge and skills was presented by Huber (2012), who distinguished:

- proximity in terms of the common technical language,

- similarity in the way of thinking about technology or products,

- similarity in terms of detailed technical solutions and arrangements (know-what),

- similarity in terms of the know-how (how to produce and solve problems).

Knoben and Oerlemans (2006) had already noticed that there are serious differences in understanding organisational proximity. In sensu largo, organisational proximity is contrasted with geographical proximity, and includes those actors who belong to the same relationship space (Oerlemans and Meeus, 2005). In sensu stricto, organisational proximity describes the degree to which organisations share practices, customs and incentive mechanisms (Metcalfe, 1994). In economic geography, it is most commonly assumed that we can talk about organisational proximity when enterprises belong to the same owner, the same industrial group (Balland, 2012; Godart, 2015) or, more generally, to the same network (Oerlemans and Meeus, 2005). A simplified measurement of proximity is present in studies using a network-based approach. An example would be the division of entities into two sectors of activity (academic and non-academic) or into public or private organisations (Broekel and Boschma, 2012).

It can be assumed that those actors who share the same network of social relations, especially personal relations, are characterised by social proximity (Oerlemans and Meeus, 2005). Hence, social proximity is sometimes called personal (personal proximity; Schamp et al., 2004), because it involves friendship relations, camaraderie relations, and trust relations (Boschma, 2005). The 
measurement of social proximity is also not easy. It would be best to capture it with the help of network distance between actors in a social network, which is actually quite often used (Balland, 2012; Crescenzi et al., 2013). However, the social network is not always identified on the basis of strong and permanent links - they are often short-term or one-time cooperation relationships. In the case of social proximity, dichotomous variables are also used relatively often in modelling. An example would be the research of Broekel and Boschma (2012), conducted in Dutch enterprises of the aviation sector, in which entities that were close in terms of social relationships were considered to be those in which board members had previously worked in former Fokker factories. However, the operationalisation of social proximity should be based mainly on qualitative variables and include the measurement of trust in a partner (Aguilera et al., 2015), the assessment of the scope of previous cooperation of actors in the past (Frenken et al., 2010), and the duration of acquaintance with the main partner (Aguilera et al., 2015). The background of a relatively poor operationalisation of the social dimension of proximity is positively influenced by an interesting suggestion from Huber (2012), who postulated the distinction of three degrees of social proximity and their qualitative measurement:

- mutual acquaintance: the degree to which one's private life is known;

- emotional proximity: the degree to which a person cares about the good of the other;

- sense of personal commitment: the degree to which an individual feels obliged to help when the other person asks for it, and this would require a considerable amount of time.

Institutional proximity includes common standards, customs (e.g. cultural, ethnic and religious), accepted practices, rules and laws regulating the relations between individuals and groups, as well as the principles of the functioning of business entities (Boschma, 2005; Broekel and Boschma, 2012). Therefore, institutional proximity refers to culturally or politically based relations (Talbot, 2010). The recognition of institutional proximity is characterised by the greatest simplifications. In this case, close entities are often understood as those that have the same institutional form, assuming that they also share a system of standards and principles (Ponds et al., 2007). Most often, the division based on the triple helix model (Etzkowitz and Leydesdorff, 2000) is used here in enterprises, scientific research units and public administration institutions. Sometimes the aforementioned triad is supplemented with a fourth category, i.e. non-profit organisations (Balland, 2012). Due to problems with operationalisation, Broekel and Boschma (2012) in their analysis of proximity in the aviation sector analysed only four of its dimensions, ignoring institutional proximity.

Although being considered as a construct that is easy to operationalise, geographical proximity is also a complex concept (Torre and Rallet, 2005). One can, therefore, distinguish the following two dimensions of geographical proximity: 
- objective proximity - real, defined in a given coordinate system, in which physical, economic or temporal distances can be measured. Objective proximity results from spatial accessibility (understood as accessibility) and is associated with overcoming space;

- subjective proximity (Aguilera et al., 2015) - resulting from the perception of real space and distances existing in it. This perception can result from one's own experience of travelling a distance. Sometimes, however, this subjective assessment results from other people's verbal accounts, media coverage, and distance images from books or magazines. It is worth remembering that this assessment considers, e.g. the exaggerated values of infrastructure equipment indicators or network congestion.

Geographical proximity can occur on three spatial scales: macro, meso, or micro. The first has an international scale, the second - an inter-regional or inter-city scale, and the third - an intra-city scale (this can, for example, be expressed by the presence in the same coworking space or the same business incubator; see Spinuzzi, 2012). In proximity economics, it is generally agreed that co-location does not simply lead to larger knowledge interactions and innovation (Boschma, 2005).

In the case of CSs, geographical proximity is often equated with physical proximity (Parrino, 2015). The physical proximity paradox consists of the fact that stronger cooperation occurs between distant and not close partners (Boschma and Frenken, 2010). Using the example of the ICT cluster in Montreal, Ben Letaifa and Rabeau (2013) showed that geographical proximity could even be a barrier to communication and knowledge flows.

Likewise in the context of knowledge networks in economic geography, it is also argued that close physical proximity does not simply imply collaboration and "co-locating people in a CS help but applying the right strategic tools can enhance the effect" (Cabral and van Winden, 2016). There are various spatial strategies that encourage interaction between the users of CSs (Cabral and van Winden, 2016; Orel and Alonso Almeida, 2019). Cabral and van Winden (2016) identified forces affecting interaction and analysed four management strategies which CSs spaces can employ to boost interaction and foster innovation. One of them is related to the supportive role of CSs' design (Orel and Alonso Almeida, 2019). Understood as a good look or feel of a work environment, a CS' friendly ambience, constitute spatial comfortability of a CS (Orel and Alonso Almeida, 2019). However, the attractiveness and aesthetics of a space does not matter for collaboration. Common physical areas (e.g. central shared meeting hub) which enable physical proximity are perceived to enhance knowledge interactions (Cabral and van Winden, 2016).

Proximity dimensions interact with each other. The large amount of relations between various dimensions of proximity is complementary. Geographical proximity is believed to enhance other dimensions of proximity (Broekel and Boschma, 2012), especially the social one (Boschma, 2005). Balland et al. (2015) and Huber 
(2012) argued that strong social ties and cognitive proximity (especially in terms of common technical language) compensate for spatial proximity. It holds true for IT firms and freelancers (Huber, 2012) who are crucial users of many CSs. Cognitive proximity is essential in the common understanding and is highly necessary to establish collaboration (Huber, 2012). The lack of institutional proximity may be compensated by geographical proximity (Boschma, 2005).

\section{RESEARCH GAPS AND CHALLENGES}

\subsection{Defining coworking spaces}

Almost every CS provides its own definition of co-working. Hence, unfortunately, there is no shared interpretation of CSs (Spinuzzi, 2012; Ivaldi et al., 2018). This is due to the fact that CSs represent significant differences in their offer, type of space, number of users, business models, work culture, shared common values, etc. (Parrino, 2015).

Capdevila (2017) argued that Fab Labs, hackerspaces, makerspaces and CSs should be treated as subsegments of a broader umbrella term "collaborative spaces" which are "localized spaces that offer open access to resources" (Capdevila, 2017). To stress their physicality, the epithet 'localised' is often added (Capdevila and Moilanen, 2013; Capdevila, 2017). Lately, Capdevila (2017) narrowed his perspective and distinguished the term "localised space of collective innovation", which puts a stronger emphasis on invention and technology sharing. However, neither collaboration nor collective innovation in CSs is automatic (Bilandzic et al., 2013). In his ethnographic study, Butcher (2013) focused on learning as the process which leads to collective innovation and recognised how co-workers learn. They learn to become collaborative, intentional, and to perform contestation (develop practices that contest entrepreneurial orthodoxies and to introduce changes) (Butcher, 2013). Castilho and Quandt (2017) studied two mechanisms of the development of collaborative capability. 'Convenience Sharing' tends to foster collaborative capability through knowledge sharing, whereas in the Community Building model CSs tend to foster collaborative capability by enhancing a creative field and individual action for the collective. Bouncken et al. (2018) focused on the coopetition in CSs: collaborative efforts may lead to the creation, but also to appropriation of values. Bouncken et al. (2018) found that the increasing of the level of openness in CSs drives a coopetition tension. The vast majority of papers reveal that there are additional efforts (especially managerial ones - Brown, 2017) necessary in order to stimulate knowledge interactions between CSs' users. Physical proximity per se cannot be treated as the only prerequisite of collaboration or innovation. 
Capdevila (2017) has argued that the combination of exploitation (not exploration) of knowledge and bottom-up (not top-down) governance system is what distinguishes CSs from other localised spaces of collective innovation. CSs are classically established and led by bottom-up counter-movements (Lange and Bürkner, 2018), although it changes dramatically when large chains of CSs emerge. From a real-estate market perspective, CSs may be classified into the broader category of multi-tenant offices. This consists of several subgroups: shared offices (offering workspaces with a high level of services), incubators and accelerators (offering services for innovative start-ups), and CSs (Weijs-Perrée et al., 2019). Waters-Lynch et al. (2016) identified three features that distinguish CSs from serviced offices: the profiles of the original co-workers, the centrality of social interactions, the aesthetic design of the spaces themselves. The relationships between CSs and other forms of collaborative spaces are shown in Fig. 2.

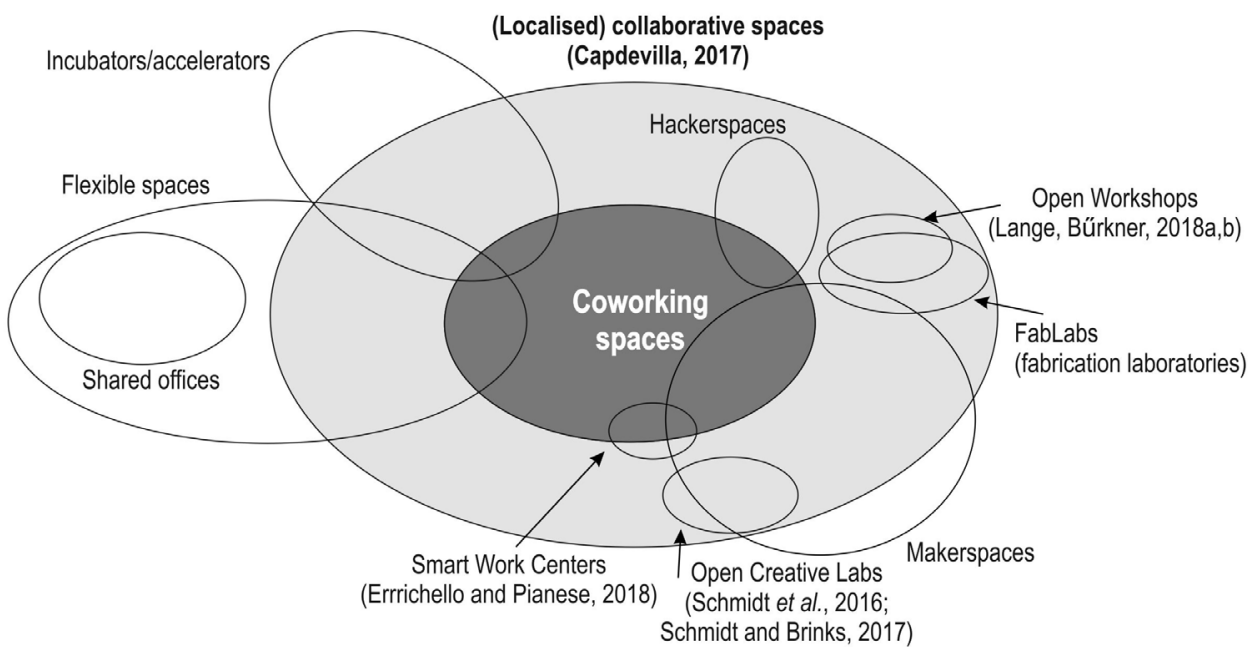

Fig. 2. Relations between various forms of collaborative spaces

Source: own work.

The most common and followed by the majority of scholars definition of coworking spaces (understood as a special subsegment of collaborative spaces) has been provided by Spinuzzi (2012, p. 399), for whom CSs are "open-plan office environments in which they work alongside other unaffiliated professionals for a fee." However, this definition neglects the most important feature of CSs that differentiates them from shared offices. Many authors (Butcher, 2013; Capdevila, 2015; Bouncken et al., 2018) have rightly argued that one of the most important features of CSs is their focus on knowledge-sharing dynamics (even if it is some- 
times limited due to managerial weaknesses; see Brown, 2017) ${ }^{3}$. What differentiates CSs from other types of collaborative spaces is that co-working is "an atmosphere, a spirit, and even a lifestyle" (Moriset, 2014, p. 7). Based on a systematic review of the literature, some common features of CSs and corresponding proximity dimensions which are enhanced by each feature were distinguished (Table 1).

Table 1. Characteristic features of CSs and corresponding proximity dimensions

\begin{tabular}{|l|l|l|}
\hline \multicolumn{1}{|c|}{ Feature of CS } & \multicolumn{1}{|c|}{ References } & Proximity dimension \\
\hline $\begin{array}{l}\text { Specific physical location (the } \\
\text { same for each individual) }\end{array}$ & $\begin{array}{l}\text { Kojo and Nenonen, 2016, 2017; } \\
\text { Howell and Bingham, 2019 }\end{array}$ & Physical proximity \\
\hline $\begin{array}{l}\text { Work alongside colleagues, and } \\
\text { companies in a flexible setting }\end{array}$ & $\begin{array}{l}\text { Spinuzzi, 2012; Fuzi, 2015; } \\
\text { Gandini, 2015; Gerdenitsch } \text { et al., } \\
\text { 2015; Merkel, 2015; Parrino, } \\
\text { 2015; Ivaldi } \text { et al., 2018; Orel and } \\
\text { Kubátová, 2019 }\end{array}$ & Social proximity \\
\hline $\begin{array}{l}\text { Temporary character of work } \\
\text { (renting a desk on a monthly, } \\
\text { weekly, daily or even hourly basis }\end{array}$ & $\begin{array}{l}\text { Merkel, 2015; Mariotti } \text { et al., } \\
\text { 2017 }\end{array}$ & Temporary proximity \\
\hline $\begin{array}{l}\text { Specific design (usually open } \\
\text { plan) }\end{array}$ & $\begin{array}{l}\text { Fuzi, 2015; Akhavan } \text { et al., 2019 } \\
\text { Kojo and Nenonen, 2017 }\end{array}$ & Physical proximity \\
\hline $\begin{array}{l}\text { Resulting social and knowledge } \\
\text { interactions and collaboration } \\
\text { within CSs }\end{array}$ & $\begin{array}{l}\text { Capdevila, 2015; Gandini, 2015; } \\
\text { Parrino, 2015; Bouncken } \text { et al., } \\
\text { 2018; Weijs-Perré } \text { et al., 2019 }\end{array}$ & Social proximity \\
\hline Shared common values and norms & Moriset, 2014; Brown, 2017 & Institutional proximity \\
\hline
\end{tabular}

Source: own work.

Some authors emphasise the fact that CSs should be membership-based offices (Orel and Kubátová, 2019; Howell and Bingham, 2019). Membership of a social or professional community is not, however, a distinct feature of all CSs. What is supposed to be a feature of 'real CSs' is the sharing of common norms, values, and beliefs, i.e. institutional proximity.

In terms of the operations of CSs, at least five spatially important, differentiating dimensions should be considered. First, there is the users-related dimension. Surprisingly, there is a gradual shift in terms of new tenants in the direction of non-classical users. The recent large-scale survey by Coworker (2019 CMCAs, 2019) has revealed that dominant groups of CSs' users are small and medium enterprises and start-up teams $(37.93 \%$ and $27.12 \%$ of coworking space,

\footnotetext{
${ }^{3}$ The distinction between 'real CSs' that practically share common norms and focus on collaboration by their 'curation' (Brown, 2017) by managers and 'fake CSs' that are only theoretically engaged in collaboration, should be made. The latter type is often represented by corporate (chain) CSs.
} 
respectively). Traditional users of CSs such as freelancers, remote workers and digital nomads (Orel, 2019) form the minority. Second, there is the industry dimension. Due to their nature, CSs attract knowledge service sector firms and individuals (Reuss and Ressia, 2015). We assume that organisation and knowledge sharing in CSs does not differ between industries, as it rather varies between different types of owners and users. Bouncken et al. (2018) recognised four different types of CSs based on value creation and appropriation. The identified types (the corporate coworking-space, the open corporate coworking-space, the consultancy coworking-space, and the independent coworking-space) differ also in terms of CSs' ownership. Third, regarding the country dimension, CSs grow in advanced economies. However, there is a large difference between the understanding and the operations CSs in North America and Europe. The majority of new working ecosystems in the US are corporate driven CSs whereas there are some local community driven examples of CSs of Europe. Fourth, regarding the local and regional dimension, it must be emphasised that co-working is still mainly an urban phenomenon, narrowed to a limited number of 'creative cities' (e.g. New York, San Francisco, London, Paris, Berlin, Amsterdam, and Barcelona, but also in megacities in Asia, South America and Australia) (Moriset, 2014). However, more and more CSs emerge in peripheral urban settings (Salone et al., 2017), small towns and less populated regions (Fuzi, 2015; Avdikos and Merkel, 2019). Fifth, the micro-local dimension of CS operations should be definitely distinguished. This includes: the type of the building being used, e.g. whether it is of mixed use or solely dedicated to CS (Ross and Ressia, 2015). There are also other dimensions that differentiate CSs (Ross and Ressia, 2015). They include, e.g. the period of membership and CSs' ownership (community workspaces vs. professionally and/ or privately run centres) (Ross and Ressia, 2015). However, these dimensions are not relatively important for the spatial dimension.

Business incubators and flexible spaces (Fig. 2) often provide co-working opportunities, but a real CS should be dedicated to generating collaboration. Incubators and accelerators ${ }^{4}$ focus on the support and development of new businesses (Fuzi, 2015) and offer the necessary services to conduct business activities. CSs are not mainly focused on this, but provide a working environment to independent workers (Fuzi, 2015) in order to concentrate on creating a community (Weijs-Perrée et al., 2019).

Apart from CSs, there is a wide variety of other collaborative spaces. In the US context, collaborative spaces are often wrongly used interchangeably with the term 'makerspace' (Amato, 2017; van Holm, 2017) and incorrectly include Fablabs (fabrication laboratories) and hackerspaces as types of makerspaces.

\footnotetext{
${ }^{4}$ There are differences between incubator and accelerator models. It does not only include much longer history of the former, but also the usual seed funding in exchange for equity in the latter (Waters-Lynch et al., 2016).
} 
In fact, Fablabs are distinct from makerspaces. Like open workshops, Fablabs tend to focus on providing and maintaining tools and equipment for the actions of individuals (the 'do-it-yourself' approach). The main idea behind these is to enable invention, design, testing, monitoring, and analysis (Mikhak et al., 2002). Hackerspaces and makerspaces tend to focus on community building (the 'do-it-together' model). Besides community building, makerspaces may provide access to machines and tools (e.g. milling machines or laser cutters) (van Holm, 2017). Hence, not only services, but also products are offered by individuals and firms operating in makerspaces. However, there is an additional rationale behind naming a given spaces a 'makerspace', i.e. when the organisation wants to be perceived as the element of the so-called 'maker movement'. The term 'hackerspace' calls back to the old-school laissez-faire underground computer clubs.

In Europe as the equivalent of fabrication laboratories, the concept of 'open workshops' has emerged in Germany. These common working spaces comprise highly innovative and diverse elements such as "prototyping technologies, 3D printing, screen printing, traditional crafts, bicycle repairing, and others" (Lange and Bürkner, 2018, p. 96). Like Fablabs, open workshops are set up to test, experiment and integrate various technologies and solutions.

The concept of 'smart work centers' (Errichiello and Pianese, 2018) resembles the construct of CSs as analysed the most. They are organised as innovative open spaces of collaboration stemming from flexible work arrangements, in particular "smart working, i.e. a holistic approach to managing employee flexibility that is able to overcome drawbacks attributed to homeworking" (Errichiello and Pianese, 2018, p. 14). Smart work centres are creative workplaces, so the work environment is organised to influence individuals' creativity. Brinks (2019) has recently introduced the term 'open creative lab' that could be categorised under the makerspace model. Open creative labs provide work stations, infrastructure and technologies to various users and are based on the flexible membership model with low entry barriers (Schmidt et al., 2016; Brinks, 2019).

To sum up, real CSs may be classified under the broader category of 'collaborative spaces' even if collaboration is sometimes fragile. Interactions together with the presence of the necessary infrastructure and specific design, provide a dynamic and inspiring milieu for collaboration, knowledge sharing and collective innovation (Butcher, 2013; Moriset, 2014; Castilho and Quandt, 2017; Bouncken et al., 2018). This should be treated as a precondition for a given space to be termed a real CS.

Unfortunately, the distinction into the subtypes of collaborative spaces is currently becoming more fuzzy, when in recent years growing number of CSs is attracting SMEs and start-ups (2018 Coworking Forecast, 2018). Moreover, more and more incubators and accelerators are getting open on providing space for independent workers. 


\subsection{Operationalisation of proximities in coworking spaces}

In this sub-section I shall translate the multidimensional construct of proximity, formerly used in meso and macro scales, into a microscale of social and economic relations present in CSs. In order to measure the various proximities between individuals or firms operating in CSs, there is a need to go beyond a simple, descriptive analysis, often based on selected quotations. The best solution would be to extend conducted interviews in order to identify all important stakeholders for a given CS. Next, social network analysis should be applied. This would make it possible to visualise and measure distances both between insiders and outside agents. Unfortunately, such analyses are rather rare. In economic geography, the only exception of using social network analysis is the research of Fiorentino (2019), who drew a social network diagram showing the interactions between the various stakeholders related to CSs in the emerging entrepreneurial ecosystem of Rome. In social sciences, the pioneering research by Parrino (2015) shed some light on the use of social networks between individuals in order to visualise links and identify the types of shared knowledge. She has drawn egocentric knowledge transmission networks for two CSs. Without considering any fundamental parameters of networks like centrality, betweenness or closeness, it was discovered that there are differences between the ranges of networks in terms of their physical scope (Parrino, 2015).

Moving to operationalisation, for internal relations in CSs, geographical proximity usually stands for physical proximity (Fig. 3) established on the micro-scale of a given collaborative space. All external links are treated as non-proximate. In terms of social proximity, friendship- and kinship-based links should be mapped. However, it would be most appropriate to apply a more specific measurement of the intensity of such relations. A good case in this respect was presented by Huber (2012), who introduced three dimensions of social proximity: knowing each other, emotional closeness, and the sense of personal obligation. The application of these three different levels of social proximity would help in assessing the strength of social ties. Parrino (2015) distinguished the types of 'know-who' knowledge that could be translated into the dimensions of social proximity. These included: occasional help for specific issues; collaborative or supplier-customer relationships; and communication or contact with third parties or introduction of/to third parties. As with the social dimension, there is a need to go beyond dummy (dichotomous) variables while measuring cognitive proximity. Huber (2012) introduced the following dimensions of cognitive proximity that may be applied to CSs: proximity regarding a common technical language; the similarity of the way of thinking about a technology or product; a similarity in terms of work-related technical details/facts (know-what); a similarity in terms of work-related know-how (how to do things or to solve a problem). In his Cambridge-focused study of the software industry he found that high levels of similarity in terms of the technical language 
are essential for understanding each other. Alternatively, backgrounds of co-workers could be also studied in order to grasp the cognitive distance between them. Allowing some cognitive distance between co-workers, it must be pointed out that basic proximity, at least in terms of technical language (Huber, 2012) is a prerequisite for collaboration.

In CSs, institutional proximity should be measured by capturing the common norms and values shared by co-workers. It must be investigated to what extent visions shared by various organisations, charters and movements such as Fab Lab Charter, the Maker Movement (Hatch, 2014; Schmidt and Brinks, 2017) or the Coworking Manifesto are commonly present and accepted by all CSs users. These documents and other charters often form the cornerstones of an organisational culture evolving in a specific collaborative environment. By building a specific culture, they contribute to institutional proximity. Brown (2017, p. 113) argued that originally co-working has been more about "an informal means of organising people who shared similar attitudes and values and who wanted to adopt a loose commitment to a shared way of working." Hence, the main idea behind the emergence of CSs (excluding real estate-driven CSs) is institutional proximity per se.

In CSs, organisational proximity is often taken for granted. However, there are different types of users (firms, freelancers, etc.) in terms of organisational forms in some collaborative spaces. According to the Coworker study (2019 CMCAs, 2019), SMEs and start-ups are becoming a more common target group in CSs than freelancers or individuals. It is rather organisational heterogeneity that stimulates collaboration and competition (Bouncken et al., 2018). Ross and Ressia (2015) applied a more nuanced perspective that the cooperation between heterogeneous members may be possible (Ross and Ressia, 2015). Ivaldi et al. (2018) and Weijs-Perrée et al. (2019) have argued that individuals should come from different business backgrounds (in terms of occupation and the sector of work, organisational status and affiliation). In contrast, Schmidt and Brinks (2017, p. 298) argued that "it is questionable whether labs in fact attract diverse groups of users."

To sum up, physical and institutional proximity constitute the foundations of CSs' operations (Fig. 3). However, institutional proximities may slightly differ between CSs. Next, in terms of importance, one should consider cognitive and social proximity. There may be even some organisational distance that should not hamper knowledge interaction.

Certainly, CSs differ in terms of the proximities established. One of the key factors that influences the process of building proximities and distances is the level of openness of CSs (Bouncken et al., 2018). Corporate CSs (Bouncken et al., 2018) introduce some cognitive and institutional proximity, but due to hierarchical relationships and organisational routines they usually do not put a major emphasis on social interactions. 


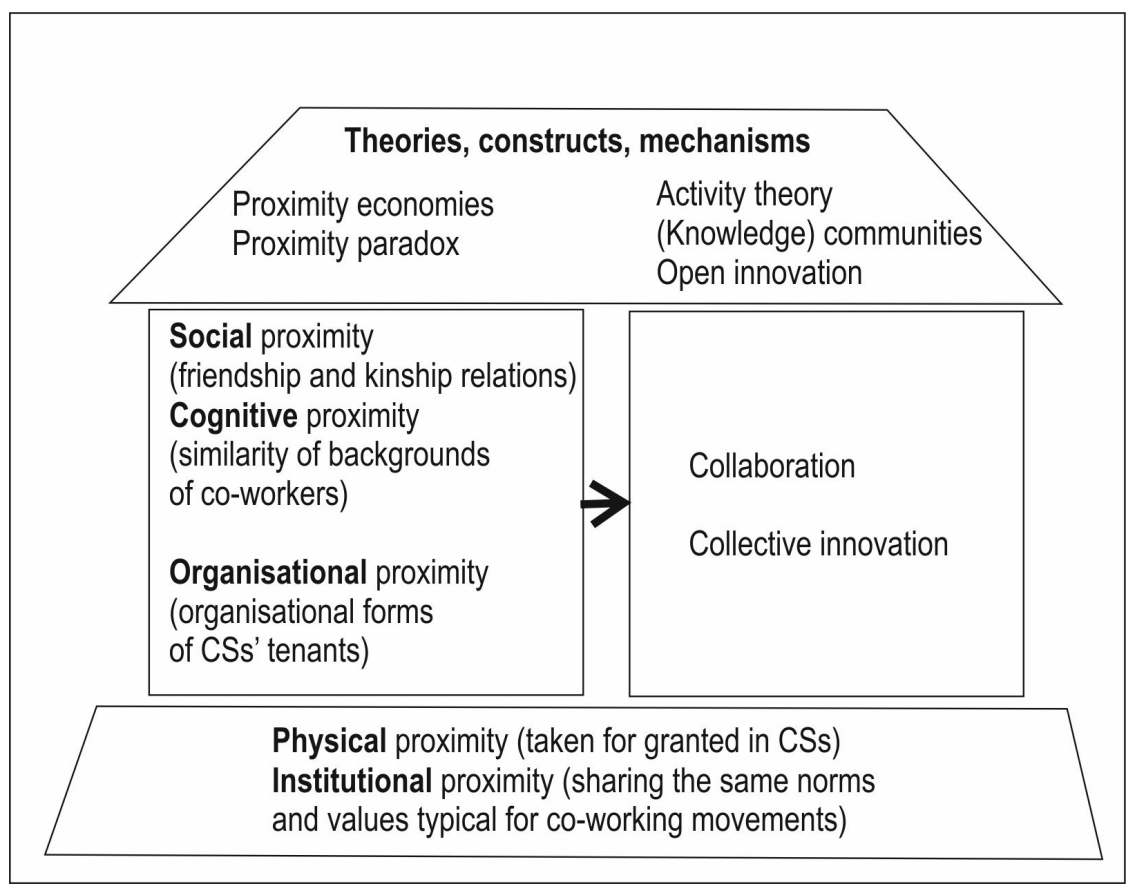

Fig. 3. Framework for proximity-based studies of CSs

Source: own work.

Open corporate CSs (Bouncken et al., 2018) introduce new institutions for collaboration, and consequently put a larger emphasis on social and institutional proximity. Consultancy coworking spaces focus on delivering some social and cognitive distance with relatively strong institutional proximity, while independent CSs mainly concentrate on strong social relationships (Bouncken et al., 2018).

\subsection{The challenges of CSs' studies}

The literature on CSs mainly relates to the field of social sciences, especially to management studies, and the spatial aspects of CSs' operations are not fully integrated with the theoretical frameworks developed within economic geography and spatial planning (Fiorentino, 2019). Hence, with the growing number of research analysing CSs, there is a need to neatly embed them in existing conceptual frameworks. Apart from proximity economics, at least three theoretical approaches related to social proximity may be applied to explain the rise and evolution of CSs in space.

First, activity theory may be applied to explain collaboration in CSs. Following Engeström (2009, p. 310), Spinuzzi (2012) argued that 'real CSs' are "bounded hubs of concentrated coordination efforts." However, it must be better understood how good 
neighbours become good partners (Spinuzzi, 2012; Brown and Ressia, 2015). In other words, the question "how unrelated activities done individually may transform into team-based collaboration" should be addressed. The fourth generation activity theory (Spinuzzi, 2012, p. 404) considers "internetworked activities by examining the interorganizational collaborations to which they contribute. These challenges correspond closely with the long-term employment trends and changes in work organization."

Second, the notion of 'communities' explains the emergence of new collaborative spaces. In this respect, communities "are regarded as entities that may exist within organizations, as alternative structures to organizations, as substitutes for organizations or as intermediaries between individuals and organizations" (Schmidt and Brinks, 2017, p. 291). Learning enables co-workers to develop a sense of community necessary to become entrepreneurially proficient (Butcher, 2013). Rus and Orel (2015) likened co-working to a community of work. CSs are also similar to the concept of cognitive and social-proximity-based 'communities of practice' (Wenger, 1998). By some authors, knowledge communities are thought to meet in CSs to collectively innovate (Butcher, 2013; Capdevila and Moilanen, 2013; Müller and Ibert, 2015). Hence, CSs can be understood as "local anchors of knowledge generated in global communities" (Schmidt and Brinks, 2017 , p. 297) or places where knowledge creation is taking place on a global scale. To sum up, conversations on the meaning of social spaces of knowledge creation may be anchored in multiple locations (Rutten, 2017).

Third, Lange and Bürkner (2018) proposed using an open innovation model (Chesbrough, 2003; Elmquist and Ollila, 2011) in studies of CS in order to refer to the recent boom observed in advanced industries which require 'open access' and a more collective understanding of innovation processes. Schmidt and Brinks (2017, p. 298) argued that "little is known about the interplay between establishing openness and securing control over an innovation."

Table 2. Main theoretical approaches and challenges of the research into CSs from the proximity perspective

\begin{tabular}{|l|l|l|}
\hline Theoretical construct/ theory & \multicolumn{1}{|c|}{ Challenge } & Proximity dimension \\
\hline $\begin{array}{l}\text { Fourth generation activity } \\
\text { theory to explain the } \\
\text { collaboration in CSs }\end{array}$ & $\begin{array}{l}\text { How do internetworked activities } \\
\text { contribute to interorganisational } \\
\text { collaborations? }\end{array}$ & $\begin{array}{l}\text { Social proximity } \\
\text { Cognitive proximity }\end{array}$ \\
\hline (Knowledge) communities & $\begin{array}{l}\text { To what extent are conversations } \\
\text { on the meaning of the social spaces } \\
\text { of knowledge creation anchored in } \\
\text { multiple locations? }\end{array}$ & Social proximity \\
\hline $\begin{array}{l}\text { Application of open } \\
\text { innovation model }\end{array}$ & $\begin{array}{l}\text { What is the interplay between } \\
\text { establishing openness and securing } \\
\text { control over an innovation? }\end{array}$ & $\begin{array}{l}\text { Social proximity } \\
\text { Cognitive proximity }\end{array}$ \\
\hline
\end{tabular}

Source: own work. 
There are at least two more challenges that should be addressed while studying CSs. First, knowledge flows, collaboration and innovation processes are strongly volatile in CSs (Parrino, 2015). For instance, all of the four innovations studied by Brinks (2019) have left collaborative spaces. Hence, due to the fact that longitudinal analyses of proximity (Balland et al., 2015, 2020) and evolution of CSs are rare, there is a need to use lenses of evolutionary economic geography in order to investigate the dynamics of CSs.

Second, in the case of CSs, the proximity paradox has not been tested so far (Boschma and Frenken, 2010). Geographically, the results of Parrino's study (2015) indicated the possibility of the existence of more links with partners outside a CS than from the same CS. Parrino (2015) has showed that this applies especially to CSs, in which there is no intra-organisational platform for the exchange of thoughts. This mechanism has not been tested on a larger sample, so it is not known whether the proximity paradox in CSs is a general rule or rather an exception. Other dimensions (social, cognitive or institutional) of the proximity paradox have not yet been tested.

\section{CONCLUSIONS}

Both proximity economics (Boschma, 2005) and scholars who study CSs (e.g. Cabral and van Winden, 2016; Brown, 2017) argue that co-location does not automatically contribute to collaboration. Physical proximity per se which is the prerequisite of defining CSs does not always result in collaboration. Conditions for collaboration and knowledge interactions may not emerge spontaneously without conscious and careful 'curation' (Brown, 2017) by a local centre champion or manager (Ross and Ressia, 2015). Such efforts may be named 'coordinated serendipity' (Liimatainen, 2015; Rus and Orel, 2015).

To sum up the definitional discussion, coworking spaces are shared venues (for short or medium-term rental) offering a facilitative milieu for social and knowledge interactions between their users. In the paper, I redefined 'real CSs' as the physical spaces of strong institutional, cognitive and, preferably, social proximities that may lead to knowledge interactions, collaboration and innovation. I have argued that even if organisational proximity in CSs is often taken for granted, there is a heterogeneity of their users. Hence, one of the main contribution of the paper involves the translation of the definition of CSs into the language of proximity economics. Based on a review of literature, I identified the characteristic features of CSs and the corresponding proximity dimensions. I also assessed the significance of various dimensions of proximity in CSs. With the use of Bouncken et al. (2018) typology I was able to indicate how proximities differ between CSs. 
The operationalisation of proximity dimensions still remains under-researched. The important message which stems from a review of the papers in proximity economics is that dichotomous (dummy) variables of proximity should be avoided. I argue that there exists a continuum of proximity (at least in reference to its social and cognitive dimension). Even if it is not possible to measure proximity using continuous variables, the non-dichotomous variables should be used to assess the level of proximity.

Taking into account the debatable role of CSs in local development, new working ecosystems should become an increasingly important focus in local and regional strategies (Fiorentino, 2019). Hence, firstly, there is a need to search for local leaders that may curate these ecosystems, because, especially in non-core areas (Brown, 2017), the major problem is to attract new members to CSs (2019 Coworking Forecast, 2019). Secondly, proper governance and support of CSs should be introduced (Waters-Lynch and Potts, 2017), especially due to the fact that CSs are strongly fragile in the era of COVID-19.

Acknowledgements. This work was supported by the Polish National Science Center under the Grant "Geographical Proximity of Knowledge-Intensive Companies and Knowledge Flows: Interactions, Mechanisms and Dynamics" (2015/17/B/HS4/00338). The content of the paper benefitted from the fruitful discussions among the members of the COST Action (CA 18214) "The Geography of New Working Spaces and the Impact on the Periphery". I'm very grateful for the insightful comments provided by two anonymous reviewers.

\section{REFERENCES}

2018 Coworking Forecast. 2018 Global Coworking Survey, Deskmag.

2019 CMCAs (Coworker Members' Choice Awards) Official Data Report, 2019, https://coworkinginsights.com/who-uses-coworking-spaces-most-common-demographics/.

2019 Coworking Forecast. 2019 Global Coworking Survey, Deskmag.

AGUilÉRA, A., LETHIAS, V. and RALlET, A. (2015), 'Spatial Proximity and Intercompany Communication: Myths and Realities', European Planning Studies, 23 (4), pp. 798-810. https:// doi.org/10.1080/09654313.2014.979137

AKHAVAN, M., MARIOTTI, I., ASTOLFI, L. and CANEVARI, A. (2019), 'Coworking Spaces and New Social Relations: A Focus on the Social Streets in Italy', Urban Science, 3 (2). https://doi. org/10.3390/urbansci3010002

AMATO, D. (2016), 'Creating a Taxonomy of Shared and Collaborative Spaces', CHI'16, May 07-12, 2016, San Jose, CA, USA. http://dx.doi.org/10.475/123 4

AVDIKOS, V. and MERKEL, J. (2019), 'Supporting open, shared and collaborative workspaces and hubs: recent transformations and policy implications', Urban Research \& Practice. https://doi. org/10.1080/17535069.2019.1674501

BALLAND, P.-A. (2012), 'Proximity and the Evolution of Collaboration Networks: Evidence form Research and Development Projects within the Global Navigation Satellite System (GNSS) Industry', Regional Studies, 46 (6), pp. 741-756. https://doi.org/10.1080/00343404.2010.529121 
BALLAND, P.-A., BOSCHMA, R.A. and FRENKEN, K. (2015), 'Proximity and Innovation: From Statics to Dynamics.', Regional Studies, 49 (6), pp. 907-920. https://doi.org/10.1080/0034340 4.2014.883598

BALLAND, P.-A., BOSCHMA, R. and FRENKEN, K. (2020), 'Proximity, Innovation and Networks: A Concise Review and Some Next Steps', Papers in Evolutionary Economic Geography, Utrecht University, Department of Human Geography and Spatial Planning, Group Economic Geography.

BASILE, R., CAPELLO, R. and CARAGLIU, A. (2012), 'Technological interdependence and regional growth in Europe: Proximity and synergy in knowledge spillovers', Papers in Regional Science, 91 (4), pp. 697-722. https://doi.org/10.1111/j.1435-5957.2012.00438.x

BATHELT, H., MALMBERG, A. and MASKELL, P. (2004), 'Clusters and Knowledge: Local Buzz, Global Pipelines and the Process of Knowledge Creation', Progress in Human Geography, 28 (1), pp. 31-56. https://doi.org/10.1191/0309132504ph469oa

BEN LETAIFA, S. and RABEAU, Y. (2013), 'Too close to collaborate? How geographic proximity could impede entrepreneurship and innovation', Journal of Business Research, 66 (10), pp. 2071-2078. https://doi.org/10.1016/j.jbusres.2013.02.033

BIANCHI, F., CASNICI, N. and SQUAZZONI, F. (2018), 'Solidarity as a byproduct of professional collaboration: social support and trust in a coworking space', Social Networks, 54, pp. 61-72. https://doi.org/10.1016/j.socnet.2017.12.002

BILANDZIC, M., SCHROETER, R. and FOTH, M. (2013), 'Gelatine: making coworking places gel for better collaboration and social learning', [in:] SHEN, H., PAAY, J., SMITH, R., WYELD, T. and CALDER, P. (eds.) Proceedings of the 25th Australian Computer-Human Interaction Conference: Augmentation, Application, Innovation, Collaboration, Association for Computing Machinery, pp. 427-436. https://doi.org/10.1145/2541016.2541027

BOSCHMA, R.A. (2005), 'Proximity and innovation. A critical assessment', Regional Studies, 39 (1), pp. 61-74. https://doi.org/10.1080/0034340052000320887

BOSCHMA, R.A. and FRENKEN, K. (2010), 'The Spatial Evolution of Innovation Networks: a Proximity Perspective', [in:] BOSCHMA, R.A. and MARTIN, R. (eds.), The Handbook of Evolutionary Economic Geography, Cheltenham, Edward Elgar, pp. 120-135. https://doi. org/10.4337/9781849806497.00012

BOTSMAN, R. and ROGERS, R. (2011), What's mine is yours: how collaborative consumption is changing the way we live, Collins, London.

BOUNCKEN, R.B. and REUSCHL, A.J. (2018), 'Coworking-spaces: how a phenomenon of the sharing economy builds a novel trend for the workplace and for entrepreneurship', Review of Managerial Science, 12 (1), pp. 317-334. https://doi.org/10.1007/s11846-016-0215-y

BROEKEL, T. and BOSCHMA, R.A. (2012), 'Knowledge networks in the Dutch aviation industry: the proximity paradox', Journal of Economic Geography, 12 (2), pp. 409-433. https://doi. org $/ 10.1093 / \mathrm{jeg} / \mathrm{lbr} 010$

BROEKEL, T., BRENNER, T. and BUERGER, M. (2015), 'An Investigation of the Relation between Cooperation Intensity and the Innovative Success of German Regions', Spatial Economic Analysis, 10 (1), pp. 52-78. https://doi.org/10.1080/17421772.2014.992359

BROWN, J. (2017), 'Curating the "Third Place"? Coworking and the mediation of creativity', Geoforum, 82, pp. 112-126. https://doi.org/10.1016/j.geoforum.2017.04.006

BUTZIN, A. and WIDMAIER, B. (2016), 'Exploring Territorial Knowledge Dynamics through Innovation Biographies', Regional Studies, 50, pp. 220-232. https://doi.org/10.1080/00343404.2 014.1001353

CABRAL, V. and VAN WINDEN, W. (2016), 'Coworking: an analysis of coworking strategies for interaction and innovation', International Journal of Knowledge-Based Development, 7 (4), pp. 357-377. https://doi.org/10.1504/IJKBD.2016.10001777 
CAPDEVILA, I. (2015), 'Co-working spaces and the localised dynamics of innovation in Barcelona', International Journal of Innovation Management, 19 (3), 1540004, pp. 1-25. https://doi. org/10.1142/S1363919615400046

CAPDEVILA, I. (2017), 'A typology of localized spaces of collaborative innovation', [in:] VAN HAM, M., REUSCHKE, D., KLEINHANS, R., SYRETT, S. and MASON, C. (eds.), Entrepreneurial neighbourhoods - towards an understanding of the economies of neighbourhoods and communities, Cheltenham, Edward Elgar Publishers, pp. 80-97. https://doi. org/10.4337/9781785367243.00013

CAPDEVILA, I. and MOILANEN, J. (2013), ‘Typologies of localized spaces of collaboration', [in:] SMEDS, R. and IRRMANN, O. (eds.), Co-Create 2013. The Boundary-Crossing Conference on Co-Design in Innovation, Conference proceedings. Aalto University Publication Series. Science and Technology, 15, pp. 15-26. https://doi.org/10.2139/ssrn.2414402

CASTILHO, M. and QUANDT, C. (2017), 'Collaborative Capability in Coworking Spaces: Convenience Sharing or Community Building?', Technology Innovation Management Review, 7 (12), pp. 32-42. https://doi.org/10.22215/timreview/1126

CHESBROUGH, H.W. (2003), Open Innovation: The new imperative for creating and profiting from technology, Harvard Business School Press, Boston.

COE, N.M. and BUNNELL, T.G. (2003), 'Spatializing knowledge communities: towards a conceptualization of transnational innovation networks', Global Networks, 3 (4), pp. 437-456. https:// doi.org/10.1111/1471-0374.00071

CRESCENZI, R., NATHAN, M. and RODRÍGUEZ-POSE, A. (2013), 'Do Inventors Talk to Strangers? On Proximity and Collaborative Knowledge Creation', Institute for the Study of Labor (IZA) Discussion Paper, 7797.

ELMQUIST, M. and OLLILA, S. (2011), 'Managing open innovation: exploring challenges at the interfaces of an open innovation arena', Creativity and Innovation Management, 4 (20), pp. 273-283. https://doi.org/10.1111/j.1467-8691.2011.00616.x

ENGESTRÖM, Y. (2009), 'The future of activity theory: A rough draft', [in:] SANNINO, A., DANIELS, H. and GUTIERREZ, K. (eds.), Learning and expanding with activity theory, Cambridge University Press, New York, NY, pp. 303-328. https://doi.org/10.1017/CBO9780511809989.020

ERRICHIELLO, L. and PIANESE, T. (2018), 'Smart Work Centers as "creative workspaces" for remote employees', CERN IdeaSquare Journal of Experimental Innovation, 2 (1), pp. 14-21.

ETZKOWITZ, H. and LEYDESDORFF, L. (2000), 'The Dynamics of Innovation: From National Systems and "Mode 2" to a Triple Helix of University-Industry-Government Relations', Research Policy, 29 (2), pp. 109-123. https://doi.org/10.1016/S0048-7333(99)00055-4

FIORENTINO, S. (2019), 'Different typologies of «co-working spaces» and the contemporary dynamics of local economic development in Rome', European Planning Studies, 27 (9), pp. 1768 1790. https://doi.org/10.1080/09654313.2019.1620697

FRITSCH, M. and SLAVTCHEV, V. (2011), 'Determinants of the Efficiency of Regional Innovation Systems', Regional Studies, 45 (7), pp. 905-918. https://doi.org/10.1080/00343400802251494

FUZI, A. (2015), 'Co-working spaces for promoting entrepreneurship in sparse regions: the case of South Wales', Regional Studies, Regional Science, 2 (1), pp. 462-469. https://doi.org/10.1080/ 21681376.2015.1072053

GANDINI, A. (2015), 'The rise of coworking spaces: a literature review', Ephemera: Theory and Politics in Organization, 15 (1), pp. 193-205.

GERDENITSCH, C., SCHEEL, T.E., ANDORFER, J. and KORUNKA, C. (2016), 'Coworking Spaces: A Source of Social Support for Independent Professionals', Frontiers in Psychology, 7 (581), pp. 1-12. https://doi.org/10.3389/fpsyg.2016.00581

GERSHENFELD, N. (2012), 'How to Make Almost Anything The Digital Fabrication Revolution', Foreign Affairs, 91 (6), pp. 41-57. 
GILL, J. and BUTLER, R.J (2003), 'Managing instability in cross-cultural alliances', Long Range Planning, 36 (6), pp. 543-563. https://doi.org/10.1016/j.1rp.2003.08.008

GODART, F.C. (2015), 'Trend Networks: Multidimensional Proximity and the Formation of Aesthetic Choices in the Creative Economy', Regional Studies, 49 (6), pp. 973-984. https://doi. org/10.1080/00343404.2012.732693

GRANDADAM, D., COHENDET, P. and SIMON, L. (2013), 'Places, Spaces and the Dynamics of Creativity: The Video Game Industry in Montreal', Regional Studies, 47 (10), pp. 1701-1714. https://doi.org/10.1080/00343404.2012.699191

HATCH, M. (2014), The Maker Movement Manifesto, McGraw Hill Education, New York.

HOWELL, T. and BINGHAM, C. (2019), 'Coworking spaces: Working alone, together', Kenan Institute Working Paper.

HUBER, F. (2012), 'On the Role and Interrelationship of Spatial, Social and Cognitive Proximity: Personal Knowledge Relationships of R\&D Workers in the Cambridge Information Technology Cluster', Regional Studies, 46 (9), pp. 1169-1182. https://doi.org/10.1080/00343404.2011.569539

IVALDI, S. (2017), Understanding coworking: Between typology and contradiction, $\mathrm{PhD}$ dissertation at Università Cattolica del Sacro Cuore di Milano, http://tesionline.unicatt.it/bitstream/10280/35572/1/Tesiphd_completa_Ivaldi_PDF.pdf.

IVALDI, S., PAIS, I. and SCARATTI, G. (2018), 'Coworking(s) in the Plural: Coworking Spaces and New Ways of Managing', [in:] TAYLOR S., and LUCKMAN S. (eds.), The New Normal of Working Lives. Dynamics of virtual work, Cham, Palgrave Macmillan, pp. 219-241. https://doi. org/10.1007/978-3-319-66038-7_11

KATZ, B. and WAGNER, J. (2014), 'The Rise of Innovation Districts: A New Geography of Innovation in America', Brookings, May 2014, https://www.brookings.edu/essay/rise-of-innovation-districts/.

KATZ, B., VEY, J.S. and WAGNER, J. (2015), 'One year after: Observations on the rise of innovation district', Brookings, 24 June 2015, https://www.brookings.edu/research/one-year-after-observations-on-the-rise-of-innovation-districts/.

KNOBEN, J. and OERLEMANS, L.A.G. (2006), 'Proximity and inter-organizational collaboration: A literature review', International Journal of Management Reviews, 8 (2), pp. 71-89. https:// doi.org/10.1111/j.1468-2370.2006.00121.x

KOJO, I. and NENONEN, S. (2016), 'Typologies for co-working spaces in Finland - What and how?', Facilities, 34 (5/6), pp. 302-313. https://doi.org/10.1108/F-08-2014-0066

KOJO, I. and NENONEN, S. (2017), 'Evolution of co-working places: drivers and possibilities', Intelligent Buildings International, 9 (3), pp. 164-175. https://doi.org/10.1080/17508975.2014 .987640

LANGE, B. and BÜRKNER, H.J. (2018), 'Flexible value creation: Conceptual prerequisites and empirical explorations in open workshops', Geoforum, 88, pp. 96-104. https://doi.org/10.1016/j. geoforum.2017.11.020

MARIOTTI, I., PACCHI, C. and DI VITA, S. (2017), 'Co-working Spaces in Milan: Location Patterns and Urban Effects', Journal of Urban Technology, 24 (3), pp. 47-66. https://doi.org/10.10 80/10630732.2017.1311556

MATTES, J. (2012), 'Dimensions of Proximity and Knowledge Bases: Innovation between Spatial and Non-spatial Factors', Regional Studies, 46 (8), pp. 1085-1099. https://doi.org/10.1080/003 43404.2011.552493

MERKEL, J. (2015), 'Coworking in the City', Ephemera: Theory and Politics in Organization, 15 (2), pp. 121-139.

METCALFE, S. (1994), 'The economic foundations of technology policy: equilibrium and evolutionary perspectives', [in:] DODGSON, M. and ROTHWELL, R. (eds.), The Handbook of Industrial Innovation, Cheltenham, Edward Elgar, pp. 409-512. 
MICEK, G. (2011), 'Estimating Multiplier Effects on the Local Scale', Acta Universitatis Lodziensis, Folia Oeconomica, 252, pp. 175-190.

MICEK, G. (2017), Bliskość geograficzna przedsiębiorstw zaawansowanego przemystu i ustug a przepływy wiedzy, Kraków, Instytut Geografii i Gospodarki Przestrzennej UJ.

MIKHAK, B., LYON, C., GORTON, T., GERSHENFELD, N., MCENNIS, C. and TAYLOR, J. (2002), Fab Lab: An Alternate Model of ICT for Development, 2nd International conference on open collaborative design for sustainable innovation, Bangalore, ThinkCycle, pp. 1-7.

MOODYSSON, J. and JONSSON, O. (2007), 'Knowledge collaboration and proximity: the spatial organization of biotech innovation projects', European Urban and Regional Studies, 14 (2), pp. 115-131. https://doi.org/10.1177/0969776407075556

MORISET, B. (2014), Building new places of the creative economy, the rise of coworking spaces, Proceedings of the 2nd Geography of Innovation International Conference, Utrecht University.

MORRISON, A. (2018) 'A Typology of Places in the Knowledge Economy: Towards the Fourth Place', [in:] CALABRO F., DELLA SPINA L. and BEVILACQUA C. (eds.), New Metropolitan Perspectives, Local Knowledge and Innovation Dynamics Towards Territory Attractiveness Through the Implementation of Horizon/E2020/Agenda2030, Springer Publishing International, Cham, pp. 444-451.

MÜLLER, F.C. and IBERT, O. (2015), '(Re-)sources of Innovation: Understanding and Comparing Time-spatial Innovation Dynamics through the Lens of Communities of Practice', Geoforum, 65, pp. 338-350. https://doi.org/10.1016/j.geoforum.2014.10.007

OERLEMANS, L.A.G. and MEEUS, M. (2005), 'Do organizational and spatial proximity impact on firm performance?', Regional Studies, 39 (1), pp. 89-104. https://doi. org/10.1080/0034340052000320896

OLDENBURG, R. (1989), The Great Good Place: Cafes, Coffee Shops, Bookstores, Bars, Hair Salons, and Other Hangouts at the Heart of a Community, Cambridge, MA, Da Capo Press.

OLDENBURG, R. and BRISSETT, D. (1982), 'The third place', Qualitative Sociology, 5 (4), pp. 265-284. https://doi.org/10.1007/BF00986754

OLMA, S. (2012), The Serendipity Machine. A Disruptive Business Model for Society 3.0, Lindonk $\&$ De Bres, Amersfoort.

OREL, M. (2019), 'Coworking environments and digital nomadism: balancing work and leisure whilst on the move', World Leisure Journal, 61 (3), pp. 215-227. https://doi.org/10.1080/1607 8055.2019.1639275

OREL, M. and ALONSO ALMEIDA, M. (2019), 'The ambience of collaboration in coworking environments', Journal of Corporate Real Estate, 21 (4), pp. 273-289. https://doi.org/10.1108/ JCRE-12-2018-0050

OREL, M. and DVOULETÝ, O. (2019), 'Transformative changes and developments of the coworking model: A narrative review', [in:] Managing Sustainable Innovation, Routledge, Taylor and Francis Group (forthcoming). https://doi.org/10.1007/978-3-030-26245-7_2

OREL, M. and KUBÁTOVÁ, J. (2019), 'Coworking as a model for conscious business', Journal of Global Responsibility. https://doi.org/10.1108/JGR-11-2018-0068

PARRINO, L. (2015), 'Coworking: Assessing the Role of Proximity in Knowledge Exchange', Knowledge Management Research \& Practice, 13 (3), pp. 261-271. https://doi.org/10.1057/ kmrp. 2013.47

PAUCEANU, A.M. and DEMPERE, J.M. (2018), 'External factors influencing Fablabs' performance', Journal of International Studies, 11 (2), pp. 341-351. https://doi.org/10.14254/2071$8330.2018 / 11-2 / 23$

PONDS, R., VAN OORT, F. and FRENKEN, K. (2007), 'The geographical and institutional proximity of research collaboration', Papers in Regional Science, 86 (3), pp. 423-443. https:// doi.org/10.1111/j.1435-5957.2007.00126.x 
RODRÍGUEZ-POSE, A. (2011), 'Economists as geographers and geographers as something else: on the changing conception of distance in geography and economics', Journal of Economic Geography, 11 (2), pp. 347-356. https://doi.org/10.1093/jeg/lbq034

ROSS, P. and RESSIA, S. (2015), 'Neither office nor home: Coworking as an emerging workplace choice', Employment Relations Record, 15 (1), pp. 42-57. https://doi.org/10.1002/ert.21500

RUS, A. and OREL, M. (2015), 'Coworking: A community of work', Teorija in Praksa, 52, pp. 1017-1038.

RUTTEN, R. (2017), 'Beyond proximities: The socio-spatial dynamics of knowledge creation', Progress in Human Geography, 41 (2), pp. 159-177. https://doi.org/10.1177/0309132516629003

SALONE, C., BONINI BARALDI, S. and PAZZOLA, G. (2017), 'Cultural production in peripheral urban spaces: lessons from Barriera, Turin (Italy)', European Planning Studies, 25 (12), pp. 2117-2137. https://doi.org/10.1080/09654313.2017.1327033

SCHAMP, E.W., RENTMEISTER, B. and LO, V. (2004), 'Dimensions of Proximity in Knowledge-based Networks: The Cases of Investment Banking and Automobile Design', European Planning Studies, 12 (5), pp. 607-624. https://doi.org/10.1080/0965431042000219978

SCHMIDT, S. and BRINKS, V. (2017), 'Open creative labs: Spatial settings at the intersection of communities and organizations', Creativity and Innovation Management, 26, pp. 291-299. https://doi.org/10.1111/caim.12220

SCHMIDT, S., BRINKS, V. and BRINKHOFF, S. (2014), 'Innovation and creativity labs in Berlin - organizing temporary spatial configurations for innovations', Zeischrift für Wiirtschaftsgeographie, 58 (4), pp. 232-247. https://doi.org/10.1515/zfw.2014.0016

SCHMIDT, S., IBERT, O., KUEBART, A. and KÜHN, J. (2016), Open Creative Labs: Typologisierung, Verbreitung und Entwicklungsbedingungen, Erkner, Leibniz-Institut für Raumbezogene Sozialforschung.

SPINUZZI, C. (2012), 'Working alone together coworking as emergent collaborative activity', Journal of Business and Technical Communication, 26 (4), pp. 399-441. https://doi. org/10.1177/1050651912444070

SUIRE, R. (2019), 'Innovating by bricolage: how do firms diversify through knowledge interactions with FabLabs?', Regional Studies, 53 (7), pp. 939-950. https://doi.org/10.1080/00343404.201 8.1522431

TALBOT, D. (2010), 'La dimension politique dans l'approche de la proximite', Géographie, Economie, Société, 22 (2), pp. 125-144. https://doi.org/10.3166/ges.12.125-144

TORRE, A. and RALLET, A. (2005), 'Proximity and localization', Regional Studies, 39 (1), pp. 47 60. https://doi.org/10.1080/0034340052000320842

VAN HOLM, E.J. (2017), 'Makerspaces and Local Economic Development', Economic Development Quarterly, 31 (2), pp. 164-173. https://doi.org/10.1177/0891242417690604

VAN WINDEN, W., DE CARVALHO, L., VAN TUIJL, E., VAN HAAREN, J. and VAN DEN BERG, L. (2012), Creating Knowledge Locations in Cities. Innovation and integration challenges, Routledge, London. https://doi.org/10.4324/9780203127162

WATERS-LYNCH, J. and POTTS, J. (2017), 'The social economy of coworking spaces: A focal point model of coordination', Review of Social Economy, 75 (4), pp. 417-433. https://doi.org/ 10.1080/00346764.2016.1269938

WATERS-LYNCH, J., POTTS, J., BUTCHER, T., DODSON, J. and HURLEY, J. (2016), 'Coworking: A Transdisciplinary Overview' (26 January 2016), available at SSRN: https://ssrn.com/abstract=2712217 or http://dx.doi.org/10.2139/ssrn.2712217

WEIJS-PERRÉE, M., VAN DE KOEVERING, J., APPEL-MEULENBROEK, R. and ARENTZE, T. (2019), 'Analysing user preferences for co-working space characteristics', Building Research \& Information, 47 (5), pp. 534-548. https://doi.org/10.1080/09613218.2018.146 3750 
WENGER, E. (1998), Communities of practice: Learning, meaning, and Identity, New York, NY, Cambridge University Press. https://doi.org/10.1017/CBO9780511803932

WOLF-POWERS, L., DOUSSARD, M., SCHROCK, G., HEYING, C., EISENBURGER, M. and MAROTTA, S. (2017), 'The maker movement and urban economic development', Journal of the American Planning Association, 83 (4), pp. 365-376. https://doi.org/10.1080/01944363.20 17.1360787

YANG, E., BISSON, C. and SANBORN, B. (2019), 'Coworking space as a third-fourth place: changing models of a hybrid space in corporate real estate', Journal of Corporate Real Estate, 21 (4), pp. 324-345. https://doi.org/10.1108/JCRE-12-2018-0051 